\title{
Posttranslational Cleavage of Proinsulin Is Blocked by a Point Mutation in Familial Hyperproinsulinemia
}

Yoshikazu Shibasaki, Toshiaki Kawakami, Yasunori Kanazawa, Yasuo Akanuma, and Fumimaro Takaku

Third Department of Internal Medicine, and Department of Physiological Chemistry and Nutrition,

Faculty of Medicine, University of Tokyo, Japan 113

\begin{abstract}
Familial hyperproinsulinemia is characterized by the accumulation of proinsulin-like material (PLM) in the plasma of affected patients. This disorder is inherited in an autosomal dominant fashion. The accumulation of PLM is thought to be due to the impaired conversion of proinsulin to insulin. Although PLM has been suggested to have an amino acid substitution, it has been impossible to locate and identify a substituted amino acid, due to the difficulty in isolating sufficient amounts of PLM from plasma samples.

Therefore, we analyzed leukocyte DNA from one member of a proinsulinemic family, and we found a point mutation that changed guanine to adenine in the insulin gene. This transition implies that a substitution of histidine for arginine has occurred at amino acid position 65 . Furthermore, it indicates that arginine at 65 is essential for the conversion of proinsulin to insulin. Our results suggest a novel mechanism by which disease can be incurred: a heritable disorder can result from a posttranslational processing abnormality caused by a point mutation.
\end{abstract}

\section{Introduction}

Insulin (composed of A chains and B chains) is derived from its precursor, proinsulin, by the removal of a connecting peptide (C-peptide). ${ }^{1}$ The cleavage is made at two pairs of dibasic residues in the proinsulin molecule; one pair is ArgArg at the junction of the C-peptide and the B-chain (C-B junction), and the other pair is Lys-Arg at the junction of the C-peptide and the A-chain (C-A junction).

Familial hyperproinsulinemia is a genetic defect in which affected members of a family have inherited increased proinsulin-like material (PLM) in an autosomal dominant fashion $(1,2)$. In these patients, immunoreactive insulin (IRI) in serum

Address correspondence to Dr. Shibasaki, Beckman Research Institute City of Hope, 1450 East Duarte Road, Duarte, CA 91010.

Received for publication 12 April 1985.

1. Abbreviations used in this paper: C-A junction, junction of the Cpeptide and the A-chain; C-B junction, junction of the C-peptide and the B-chain; C-peptide, connecting peptide; HPLC, high performance liquid chromatography; IRI, immunoreactive insulin; kb, kilobase; PLM, proinsulin-like material.

J. Clin. Invest.

(C) The American Society for Clinical Investigation, Inc.

0021-9738/85/07/0378/03 \$1.00

Volume 76 , July $1985,378-380$ is $\sim 100 \mu \mathrm{U} / \mathrm{ml}$ (normal, $\sim 10 \mu \mathrm{U} / \mathrm{ml}$ ), and $>80 \%$ of IRI is in the form of PLM. The accumulation of PLM is thought to be due to the impaired conversion of proinsulin to insulin. Three unrelated families of this disease have been reported thus far $(1,3,4)$. While one of the families (family 1) is normoglycemic (1), the family we described previously (family 2 ) is mildly diabetic (3). In the case of family 2 , we have shown that the PLM has an amino acid substitution at the CA junction of proinsulin, which results in the lack of an arginine residue (5). Although the proinsulin of family 1 was initially thought to have a substitution at the C-B junction, precise analysis using high pressure liquid chromatography (HPLC) has revealed recently that the defect is located at the same site as, or nearby site as that in the proinsulin of family 2 (6). The defect in the third case (family 3) has not yet been determined (4). In addition to these examples of abnormal proinsulins, three abnormal insulin variants have already been reported $(7,8)$. Two of these variants were analyzed at the DNA level and were found to have single point mutations in the region coding for the B-chain $(9,10)$.

To elucidate the molecular abnormality of the DNA in the case of familial hyperproinsulinemia, we examined the insulin gene of our patients.

\section{Methods}

Genomic DNA was prepared from the peripheral blood leukocytes of one member (Y.U.) of family 2 (11). Southern blot hybridization was carried out according to the published procedure (12). Cloning procedures are as follows. An EcoRI fragment of $\sim 15$ kilobases (kb), which contained the insulin gene, was isolated by agarose gel electrophoresis and electroelution, and then ligated to lambda Charon 4A arms. In vitro packaging was performed by using established procedures (13). Plaques were screened by an in situ hybridization (14) with a ${ }^{32} \mathrm{P}$ labeled human insulin gene probe (Hinc II-Bgl I, 1.6-kb fragment [15]). A 5-kb Xho I fragment containing the insulin gene was isolated from positive phage and was subcloned into the Sal I site of pBR322. Two kinds of plasmids ( $\alpha$ and $\beta$ ) were detected by digestion with Pst I. Nucleotide sequence analysis was performed by the dideoxy chain termination method $(16,17)$ and by the chemical cleavage method (18)

\section{Results}

High molecular weight DNA was prepared as described previously (11) from the peripheral blood leukocytes of a member of family 2 with hyperproinsulinemia. Southern blot hybridization (12) with the human insulin gene probe (Hinc II-Bgl I, 1.6-kb fragment) (15) revealed that there was no apparent rearrangement of the insulin gene of the patient. There was neither creation nor destruction of endonuclease restriction 
sites at the C-A junction with respect to the enzymes EcoRI, Sac I, Hind III, Mbo II, and Bgl I (data not shown). Therefore, it was necessary to determine the structural alteration in the abnormal insulin gene by nucleotide sequence analysis.

A 15-kb EcoRI DNA fragment containing the insulin gene from the patient's DNA was ligated into EcoRI-cleaved-lambda Charon 4A arms and packaged in vitro (13). Of 600,000 recombinant phages screened (14), 13 phages were found to hybridize to the cloned human insulin gene probe (15). A 5.0kb Xho I DNA fragment containing the entire human insulin gene in the recombinant phage DNA was isolated and subcloned into the Sal I site of the plasmid pBR322. A detailed restriction map of the recombinant plasmid (pYU2) is shown in Fig. 1 $B$. An abnormal clone cannot be discriminated from a normal clone by length polymorphism residing upstream of a $5^{\prime}$ flanking region (11). Moreover, there are two types of allelic variants of the insulin gene in normal people, which result from four silent mutation sites (19). These two kinds of alleles are designated $\alpha$ and $\beta$. A new recognition site of the endonuclease $P$ st $I$ in the $3^{\prime}$ flanking region is present in the $\beta$ type insulin gene. To discriminate between $\alpha$ and $\beta$ clones, we cleaved these clones by Pst I. We selected two clones from each type for sequence analysis. Fragments that include the region encoding the C-B junction were isolated by $1.5 \%$ agarose gel electrophoresis and electroelution. The sequence strategy is shown in Fig. $1 \mathrm{~B}$. DNA fragments from each clone were sequenced by the chain termination method $(16,17)$ and by the chemical cleavage method (18). The $\alpha$ type clone has the same sequence as that reported for the normal insulin gene (15). In contrast, both $\beta$ type clones were found to have a guanine to adenine transition in the C-A junction site corresponding to the arginine 65 , in agreement with our previous localization of the mutation (5), while a normal lysin 64 was present (Fig. 2). The point mutation created a new CGT codon encoding the amino acid histidine (Fig. 3).

Thus, the hyperproinsulinemic disorder in this case (family 2) results from a point mutation at the C-A junction. In contrast to the case of abnormal insulin, this mutation site does not occur in the insulin molecule itself. The disappearance of the dibasic pair (Lys-Arg) blocks the maturation of insulin (Fig. 3). As a consequence, the secreted PLM is a type II intermediate (in which the C-peptide is attached to the insulin A chain), which has been shown to have low biological activity relative to insulin (20). The defect in insulin maturation is compensated by high serum levels of PLM.

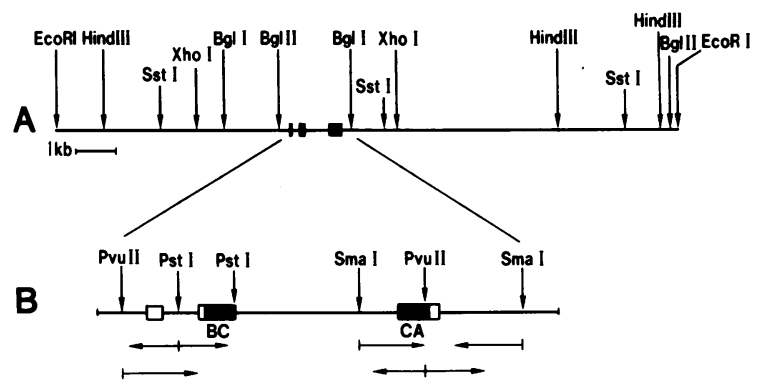

Figure 1. Restriction map and the nucleotide sequencing strategy. $(A)$ Restriction endonuclease map of the mutant allele of the patient's insulin gene. $(B)$ Strategy of nucleotide sequence analysis of pYU2. Restriction endonuclease sites are shown. The boxes represent exons and the black shaded portions indicate the polypeptide coding regions. The horizontal arrows indicate segments sequenced.

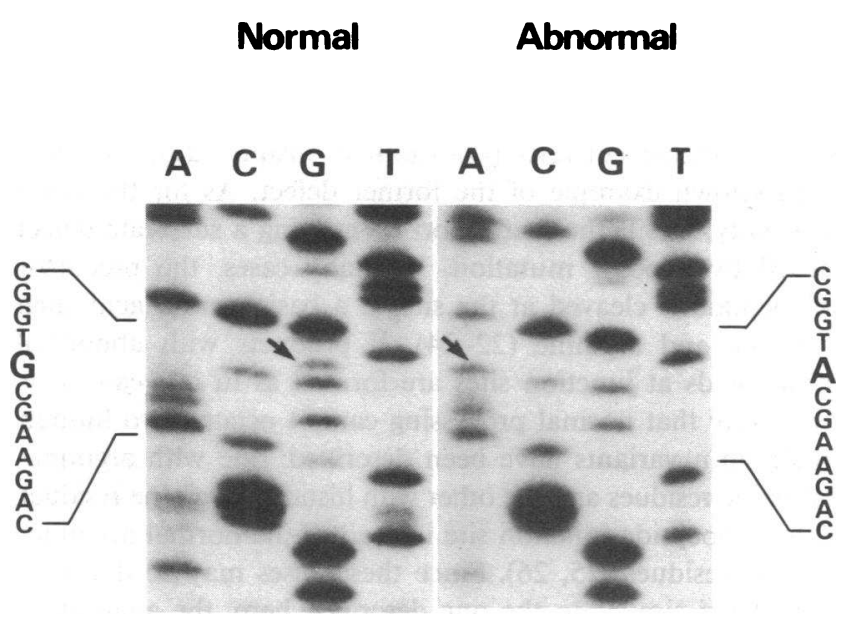

Figure 2. Autoradiograph of the sequencing gel showing the nucleotide change. The coding strands of both normal and abnormal allele DNA were sequenced by the dideoxy chain termination method $(16,17)$.

\section{Discussion}

Because the HPLC elution pattern of the PLM of family 1 is indistinguishable from that of family 2 , it is likely that the point mutation in the defective insulin gene of family 1 is also in the same arginine codon (6). As proinsulin levels are almost the same in both families, it is not clear why family 2 is mildly diabetic while family 1 is normoglycemic. The difference may arise, since the synthesis and the degradation rates of insulin as well as its structure, are important to determine the serum glucose level. However, it is possible that the substituted amino acid is different from histidine in family 1.

We determined that our patient has one normal and one abnormal insulin allele. It is reasonable to assume that these two alleles are expressed codominantly. The high ratio of PLM to insulin (9:1) probably depends not on differential gene expression but on a longer circulating half-life of the abnormal product, possibly due to a slower rate of PLM degradation (20). As this disorder is heritable, the insulin genes of other members of the family are of great interest. As described above, there is no restriction enzyme that recognizes this mutation site, and it is arduous to sequence the insulin gene of each member. However, now that the point mutation has been identified, it will be possible to make a family tree of this mutation site by hybridization with synthetic oligonucleotide probe (21).

Most secretory proteins, including peptide hormones, undergo posttranslational processing such as glycosylation and

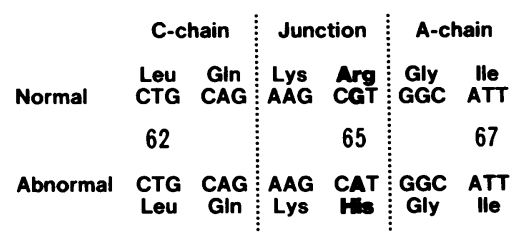

Figure 3. Comparison of nucleotide and amino acid sequence around the $C$ peptide- $A$ chain junction site. The numbers indicate the position of the amino acid from the amino terminus of the B chain. A single $G$ to $A$ transition at the codon for arginine at position 65 resulted in a histidine substitution and loss of the lysine-arginine pair. 
peptide cleavage (22). There are two possible defects in this process: (a) a processing enzyme abnormality; and (b) a precursor substrate defect. Recently, it has been reported that a thiol-protease converts proinsulin to insulin (23), but there is no known example of the former defect. As for the latter possibility, this is the first report identifying a substrate defect caused by a point mutation. In many cases, the precursor polypeptide is cleaved at the site of a basic amino acid such as lysine and arginine (22-24). If products with abnormal amino acids at junction sites are formed as in our case, it is very likely that normal processing cannot occur. Two human proalbumin variants have been described: one with arginineglutamine residues and the other with histidine-arginine residues at the propeptide junction site instead of the normal argininearginine residues $(25,26)$. Since these cases may be due to a mechanism similar to the one described here, the analysis of the albumin gene of these variants will be of interest. A point mutation corresponding to a site of posttranslational cleavage or other posttranslational processing events constitutes a new mechanism of causing inherited diseases; the frequency of this mechanism remains to be determined.

\section{Acknowledgments}

We thank Dr. G. I. Bell for his kind gift of human insulin gene probes, and Dr. P. De Meyts for useful discussions. This work is partly supported by Grant-in-aid for Scientific Research 58570993.

\section{References}

1. Gabbay, K. H., K. Deluca, J. N. Fisher, Jr., M. E. Mako, and A. H. Rubenstein. 1976. Familial hyperproinsulinemia: an autosomal dominant defect. N. Engl. J. Med. 294:911-915.

2. Gabbay, K. H., R. M. Bergenstal, J. Wolff, M. E. Mako, and A. H. Rubenstein. 1979. Familial hyperproinsulinemia: partial characterization of circulating proinsulin-like material. Proc. Natl. Acad. Sci. USA. 76:2882-2885.

3. Kanazawa, Y., M. Hayashi, M. Ikeuchi, M. Kasuga, Y. Oka, H. Sato, K. Hiramatsu, and K. Kosaka. 1979. Familial hyperproinsulinemia: a rare disorder of insulin biosynthesis. Proc. Symp. Proinsulin, Insulin and C-peptide, Tokushima, 12-14 July, 1978. Excerpta Medica, Amsterdam. International Congress Series No. 468. 262-269.

4. Gruppuso, P. A., P. Gordon, C. R. Kahn, M. Cornblath, W. P. Zeller, and R. Schwartz. 1984. Familial hyperproinsulinemia due to a proposed defect in proinsulin to insulin conversion. N. Engl. J. Med. 311:629-634.

5. Robbins, D. C., P. M. Blix, A. H. Rubenstein, Y. Kanazawa, K. Kosaka, and H. S. Tager. 1981. A human proinsulin variant at arginine 65. Nature (Lond.). 291:679-681.

6. Robbins, D. C., S. E. Shoelson, A. H. Rubenstein, and H. S. Tager. 1984. Familial hyperproinsulinemia: two cohorts secreting indistinguishable type II intermediate of proinsulin conversion. J. Clin. Invest. 73:714-719.

7. Shoelson, M., M. Haneda, P. Blix, A. Nanjo, T. Sanke, K. Inouye, D. Steiner, A. H. Rubenstein, and H. Tager. 1983. Three mutant insulins in man. Nature (Lond.). 302:540-543.
8. Tager, H. E. 1984. Abnormal products of the human insulin gene. Diabetes. 33:693-699.

9. Kwok, S. C. M., D. F. Steiner, A. H. Rubenstein, and H. S. Tager. 1983. Identification of a point mutation in the human insulin gene giving rise to a structurally abnormal insulin (Insulin Chicago). Diabetes. 32:872-875.

10. Haneda, M., S. J. Chan, S. C. M. Kwok, A. H. Rubenstein, and D. F. Steiner. 1983. Studies on mutant human insulin genes: identification and sequence analysis of a gene encoding $\mathrm{Se}^{\mathrm{B2} 4}$ insulin. Proc. Natl. Acad. Sci. USA. 80:6366-6370.

11. Bell, G. I., J. H. Karam, and R. J. Rutter. 1981. Polymorphic DNA region adjacent to the $5^{\prime}$ end of the human insulin gene. Proc. Natl. Acad. Sci. USA. 78:5759-5763.

12. Southern, E. 1975. Detection of specific sequences among DNA fragments separated by gel electrophoresis. J. Mol. Biol. 98:503517.

13. Blattner, F. R., A. E. Blechl, K. Denniston-Thompson, H. E. Farber, J. E. Richards, J. L. Slightom, P. W. Tucker, and O. Smithies. 1978. Cloning human fetal $\gamma$-globin and mouse $\alpha$-type globin DNA: preparation and screening of shotgun collections. Science (Wash. DC). 202:1279-1284.

14. Benton, W. D., and R. W. Davis. 1977. Screening $\lambda g t$ recombinant clones by hybridization to single plaques in situ. Science (Wash. DC). 196:180-182.

15. Bell, G. I., R. J. Pictet, W. J. Rutter, B. Cordell, E. Tischer, and H. M. Goodmann. 1980. Sequence of the human insulin gene. Nature (Lond.) 284:26-32.

16. Sanger, F., A. R. Coulson, B. G. Barrell, A. J. H. Smith, and B. A. Roe. 1980. Cloning in single-stranded bacteriophage as an aid to rapid DNA sequencing. J. Mol. Biol. 143:161-178.

17. Messing, J., R. Crea, and P. H. Seeburg. 1981. A system for shotgun DNA sequencing. Nucl. Acids Res. 9:309-321.

18. Maxam, A. M., and W. Gilbert. 1979. Sequencing end-labeled DNA with base-specific chemical cleavages. Methods Enzymol. 65: 499-560.

19. Ullrich, A., T. J. Dull, A. Gray, J. Brosius, and I. Sures. 1980. Genetic variation in the human insulin gene. Science (Wash. DC). 209:612-615.

20. Yu, S. S., and A. E. Kitabchi. 1973. Biological activity of proinsulin and related polypeptides in the fat tissue. J. Biol. Chem. 248:3753-3761.

21. Kidd, V. J., R. B. Wallace, K. Itakura, and S. L. C. Woo. 1983. $\alpha_{1}$-antitrypsin deficiency detection by direct analysis of the mutation in the gene. Nature (Lond.). 304:230-234.

22. Docherty, K., and D. F. Steiner. 1982. Posttranslational proteolysis in polypeptide hormone biosynthesis. Ann. Rev. Physiol. 44: 625-638.

23. Docherty, K., R. J. Carroll, and D. F. Steiner. 1982. Conversion of proinsulin to insulin: involvement of a 31,500 molecular weight thiol protease. Proc. Natl. Acad. Sci. USA. 79:4613-4617.

24. Bell, G. I., R. F. Santerre, and G. M. Mullenbach. 1983. Hamster preproglucagon contains the sequence of glucagon and two related peptides. Nature (Lond.). 302:716-718.

25. Brennan, S. O., and R. W. Carrell. 1978. A circulating variants of human proalbumin. Nature (Lond.). 274:908-909.

26. Abdo, Y., J. Rousseaux, and M. Dautrevaux. 1981. Proalbumin Lille, a new variant of human serum albumin. FEBS (Fed. Eur. Biochem. Soc.) Lett. 131:286-288. 